\title{
A EXTENSÃo COMO AÇÃo PEDAGógICA
}

\author{
EXTENSION AS PEDAGOGICAL ACTION
}

Adriano Souza $^{1}$ e Viviane de Vargas Geribone ${ }^{2}$

\begin{abstract}
RESUMO
O presente artigo corresponde à sistematização de reflexões geradas a partir da leitura e da análise de políticas públicas para a extensão universitária em âmbito nacional. Nesse sentido, as ideias suscitadas por este trabalho foram articuladas à contribuição de Paulo Freire (2011) acerca da discussão sobre extensão e apontam para a necessidade de se repensar a prática da extensão universitária a partir do seu entendimento enquanto ação pedagógica.
\end{abstract}

Palavras-chave: Extensão universitária. Políticas públicas. Ação pedagógica.

\begin{abstract}
This paper conveys a systematization of reflections generated from reading and analysis of public policies for university extension programmes nationwide. In this context, the ideas involved were articulated to a contribution of Paulo Freire (2011) discussion about extension and suggest the need to rethink the practice of university extension from their conviction as pedagogical action.
\end{abstract}

Keywords: University Extension. Public Policy. Pedagogical action.

\section{A EXTENSÃo COMO AÇÃo PEDAGÓGICA}

Conhecer é tarefa de sujeitos, não de objetos. Paulo Freire

Um breve panorama das políticas institucionais de extensão universitária no Brasil é capaz de pontuar que, em primeiro lugar, o caráter indissociável do chamado tripé ensino-

\footnotetext{
${ }^{1}$ Possui graduação em Letras: Português e Literaturas de Língua Portuguesa pela Universidade Federal de Santa Maria (2009) e Mestrado em Letras - Estudos Literários, pelo Programa de PósGraduação em Letras da UFSM (2012). Pertenceu ao quadro de Servidores Técnico-Administrativos em Educação da UFSM. Atualmente é Professor Assistente da Universidade Federal do Pampa, Campus Bagé. Email: adrianosouza@unipampa.edu.br

${ }^{2}$ Possui graduação em Letras: Licenciatura - Português e Literaturas da Língua Portuguesa pela Universidade Federal de Santa Maria (2008). Concluiu o curso de Especialização em Literatura Brasileira, no Centro Universitário Franciscano, em Santa Maria-RS (2009). Além disso, é especialista em Língua Portuguesa: da teoria à prática, pelo convênio da Universidade Castelo Branco com a Fundação Trompowsky, Rio de Janeiro-RJ (2009). Mestra em Educação pela URI-FW (2014), pertenceu ao quadro de professores nomeados do magistério estadual do Rio Grande do Sul. Atualmente é Professora Substituta do CTISM/UFSM. Email: vivianegeribone@yahoo.com.br
} 
pesquisa-extensão há muito se tornou um mito da estratégia retórica pautada pelo discurso acadêmico. É possível que isso se deva ao fato de as práticas de ensino e pesquisa formatarem-se com facilidade aos moldes do contexto neoliberal atual e as ações de extensão, mais resistentes aos encaixes programáticos dos modelos atuais de gestão educacional, oferecerem certa resistência à absorção pragmática.

Caberia, nesse sentido, investigar, em um primeiro momento, qual o sentido que viemos atribuindo ao sintagma extensão universitária, ou, em outros termos, o que compreendemos conceitualmente por ação extensionista, fato indissociável da compreensão do papel e do compromisso social das instituições universitárias. Parece que reside aqui um lúcido ponto de partida, qual seja: compreender a extensão no âmbito acadêmico e seus desdobramentos na esfera político-social significa especular sobre o papel da universidade enquanto instituição de caráter autônomo que promove e legitima o ensino superior. Resulta, portanto, antes de tudo, em ato de cidadania investigar e dirigir o exercício da dúvida ao fundamento da Constituição Federal (mais precisamente ao Art. 207) que delega às universidades brasileiras autonomia didático-científica, disciplinar, administrativa e financeira.

Sendo assim, poderíamos começar por indagar de que forma vem sendo tratada a referida autonomia de que os gestores e dirigentes das universidades devem se valer em seu ofício. Se for verdade, conforme apontamos no parágrafo introdutório, que o momento atual privilegia certo tipo de pesquisa acadêmica e as agências responsáveis por captar e alocar recursos fomentam e legitimam a prática de um certo tipo de pesquisa - o que repercute nos modos de conduzir um certo tipo específico de prática de ensino e que tanto essa prática atual de ensino como os modelos de pesquisa parecem não estabelecer comunicação com a natureza social e humanista reservada, como veremos, às ações de extensão -, deveríamos então dirigir nossas indagações no sentido de averiguar para quem está sendo construída a referida autonomia, ou, em outras palavras, autonomia didático-científica e administrativo-financeira de quem? Em relação ao quê? e para quem?

De posse dessas perguntas, convém dirigirmos o olhar para o que os documentos dizem. Especificamente no Brasil, na Lei que regulamenta as Diretrizes e Bases para a Educação (Lei No 9.394/96), em seu Art. 43, temos que a Educação Superior tem por finalidade promover a extensão, “aberta à participação da população, visando à difusão das conquistas e benefícios resultantes da criação cultural e da pesquisa científica e tecnológica geradas na instituição". E que, além disso, é finalidade da Educação Superior "estimular o 
conhecimento dos problemas do mundo presente, em particular os nacionais e regionais, prestar serviços especializados à comunidade e estabelecer com esta uma relação de reciprocidade".

No sentido que aí está, parece possível e bastante didático inferir que, enquanto universidade, temos por finalidade conhecer os problemas do mundo presente e, de posse disso, articular modos de agir junto à comunidade na tentativa de solucionar os problemas existentes. Estaria aí, já na LDB, um relevante entendimento de um conceito de extensão universitária e, junto a este entendimento, une-se também uma dúvida de aparência um tanto ingênua: vejamos, a partir de uma rasa e apressada leitura do momento atual, que nos brinda com uma esplendorosa expansão de cursos superiores e vagas em universidades, poderíamos concluir que nunca se estudou tanto os problemas brasileiros como atualmente. Ora, se temos por finalidade conhecer os problemas locais e agir para dissipá-los, e, como os números mostram, nunca houve tanta gente nas universidades estudando, dentre outras coisas, os problemas do mundo, por que, então, em países como os da América Latina, convivemos ainda com problemas pré-históricos como o analfabetismo e suas derivações (analfabetismo funcional, analfabetismo digital e tantos quantos mais possam haver), como a má distribuição de renda e de terras para a agricultura familiar, como o desigual acesso a tratamentos de saúde?

Respostas a perguntas como essa podem surgir desde variados pontos de vista. Frente a essas diretrizes de matrizes ideológicas mais variadas, faz-se necessário questionar a partir de que quadro de referências orientador da sociedade tal resposta está sendo proposta. Em outras palavras, mais do que a resposta em si, deveria interessar-nos sua posição assumida no âmbito político do discurso em que se inscreve. Nessa perspectiva, as possibilidades quase sempre são duas, não por simplificação esquemática ou reducionismo, mas pelo próprio sentido de natureza conflituosa que caracteriza a batalha ideológica. Portanto, ou bem se defende a manutenção da ordem, ou bem se defende sua mudança; enfrenta-se o problema com pequenos reparos formais ou procura-se a raiz do problema; assume-se o ponto de vista da lógica do capital ou enfrenta-se a possibilidade de rompê-la.

É preciso, com efeito, considerar que a análise e, mais do que isso, a implantação de políticas públicas como a descrita anteriormente, parte, inexoravelmente, por considerar o modo capitalista de organização da reprodução econômica e social como quadro de referência orientador de suas práticas. Daí que se torna comum observar que, em geral, o problema ajusta-se à solução, pois esta é sempre uma solução permissível dentro do metabolismo da 
atual lógica economicamente hegemônica. As soluções que, por ventura, desafiem a lógica autoritária global do capital e que cheguem por meio de mudanças institucionais isoladas, em geral, tendem a fracassar, pois a "legitimação constitucional democrática" do Estado capitalista defende apenas os seus próprios interesses. (MÉSZÁROS, 2008, p.61)

Ainda nessa mesma linha temática, descortinando um pouco mais os preâmbulos da referida Lei de Diretrizes e Bases para Educação Nacional, sobretudo no que se refere à Educação Superior, temos ainda, articulando textualmente os incisos VII e X do Art. 53º que no exercício da dita autonomia é assegurado às universidades firmar contratos, acordos e convênios no sentido de receber subvenções, doações, heranças, legados e cooperação financeira resultante de convênios com entidades públicas e privadas. Nesse sentido, torna-se pertinente apontar que, se podemos, no uso de nossa autonomia, firmar contratos, acordos e convênios com vistas a receber subvenções e cooperações financeiras - e de fato é possível apontar que as universidades têm cada vez mais atraído o interesse de iniciativas privadas sedentas em firmar convênios e contratos - podemos concluir que dispomos de algum tipo de material concreto-tecnológico ou teórico-intelectual que é fruto do interesse de contratantes e agenciadores de convênio. Isto porque, e não há nenhum brilhantismo nesta dedução, segundo a lógica do capital, se há investimento é porque deve haver lucro a curto, médio ou longo prazo. Do que facilmente depreendemos um deslocar-se a discussão do âmbito educacional para o terreno da economia da educação, troca-se inclusive a terminologia, e passamos a empregar a linguagem dos negócios, dos agenciadores, terminologia que ignora os conceitos do terreno educacional como educador-educando e educando-educador, os quais passam a ser vistos como demandante, ofertante, proponente, etc.

A educação em sentido amplo deveria ser o terreno privilegiado em que o trabalho do homem não tem como fim modificar a natureza através da criação de objetos que se apartam do seu fazer. Pois, em educação, o trabalho dos homens e mulheres não visa a modificar a natureza pela criação de objetos, que passam a mediar as práticas sociais. Em educação, servimo-nos de objetos como mediadores de pensamentos; como mediadores de comunicação; como mediadores de reflexões.

Entretanto, servir-se dos objetos como mediadores de comunicação reflexiva não é apenas privilégio da educação, já que esta prática é o ponto de partida das relações humanas e é a essência da natureza dialógica da linguagem. O que se espera, portanto, que difira a educação de outras práticas humanas é que, em educação, as relações mediadas por objetos sejam construções que contribuam e motivem os homens e mulheres para a mudança e para a 
transformação do mundo objetal - não construindo objetos - mas construindo sensibilidades geradoras de ações éticas e políticas que fundamentem a estrutura moral dos sujeitos. Fundamentar estruturas morais, através de ações éticas e políticas é conscientizar, não doutrinar. Espera-se que um sujeito educador-educando - um sujeito cuja estrutura moral tenha sido fundamentada dentro da ética da conscientização - seja um sujeito politicamente atuante, seja um sujeito que reaja ante a injustiça e a hostilidade, seja um sujeito que trabalhe para superar a ordem econômica em que o homem é explorado pelo homem.

Para evitar que isso aconteça no capitalismo, os proprietários da força produtiva e dos objetos transformaram também o mundo da educação em um mundo objetal, no qual o trabalho do homem deve ser o de construir objetos que se apartam de si, e não o de se valer de objetos existentes para mediatizar a conscientização. Como ferramenta fundamental à dinâmica capitalista, a educação, cooptada pelo discurso neoliberal, é transformada em capital humano e associada às leis do mercado, ao livre comércio, tornando-se uma importante mercadoria paragarantiados parâmetros reprodutivos do sistema do capital. A educação formal está amarrada a esse complexo organismo metabólico autocentrado, e não se trata apenas da educação básica, as universidades por meio de suas ações de extensão, projetos de pesquisa e planos de ensino, pela forma como exercem sua referida autonomia, pela forma como articulam seu saber com a sociedade civil são peça chave para a compreensão dessa dinâmica.

Sendo assim, não podemos entrar nessa discussão ignorando que já em 1968 - muito antes, portanto, dessa LDB que hoje temos às mãos, antes, inclusive, de se haver institucionalizado a questão da extensão por meio dos fóruns pertinentes - o educador Paulo Freire (2011) já estava, em território chileno, a problematizar o conceito de extensão. Ao professor, nessa época, interessava extrair os pressupostos fundamentais da relação entre agrônomos e camponeses chilenos mediada pela chamada extensão rural e as consequências dessas relações na construção da reforma agrária, pelo conceito de asentamiento. Nesse percurso, Paulo Freire, apresenta-nos uma análise semântica do termo extensão, para criticar a chamada "força operacional" do conceito, através da qual a prática extensionista adquire uma dimensão antidialógica. Nesse sentido, a extensão é vista tão-somente como o ato de se estender mecanicamente um conhecimento, uma tecnologia, uma técnica de um ser que as detém suficientemente (detém esse conhecimento, essa tecnologia e essa técnica de forma plural) para outro ser, que é reduzido a um mero objeto desse tipo de fazer. 
É preciso, com efeito, pontuar que,para fins de sistematização destas ideias, por extensão universitária estamos pensando de forma deliberada nos princípios que, anos mais tarde, vieram a nortear as políticas públicas de extensão.Princípios estes - diga-se de passagem referendados anualmente nos âmbitos institucionais pertinentes ${ }^{1}$ - que parecem comungar, como veremos, dos pressupostos críticos de Paulo Freire (2011) e que podem ser definidos a partir das seguintes diretrizes:

1. a ciência, a arte e a tecnologia devem alicerçar-se nas prioridades do local, da região, do País;

2. a Universidade não pode imaginar-se proprietária de um saber pronto e acabado, que vai ser oferecido à sociedade, mas, ao contrário, exatamente porque participa dessa sociedade, ela deve ser sensível a seus problemas e apelos, sejam os expressos pelos grupos sociais com os quais interage, sejam aqueles definidos ou apreendidos por meio de suas atividades próprias de Ensino, Pesquisa e Extensão;

3. a Universidade deve participar dos movimentos sociais, priorizando ações que visem à superação da desigualdade e da exclusão social existentes no Brasil;

4. a ação cidadã das Universidades não pode prescindir da efetiva difusão e democratização dos saberes nelas produzidos, de tal forma que as populações, cujos problemas se tornam objeto da pesquisa acadêmica, sejam também consideradas sujeito desse conhecimento, tendo, portanto, pleno direito de acesso às informações resultantes dessas pesquisas;

5. a prestação de serviços deve ser produto de interesse acadêmico, científico, filosófico, tecnológico e artístico do Ensino, Pesquisa e Extensão, devendo ser encarada como um trabalho social, ou seja, ação deliberada que se constitui a partir e sobre a realidade objetiva, produzindo conhecimentos que visem à transformação social;

6. a atuação junto ao sistema de ensino público deve se constituir em uma das diretrizes prioritárias para $\mathrm{o}$ fortalecimento da educação básica através de contribuições técnico-científicas e colaboração na construção e difusão dos valores da cidadania.

À luz desses princípios, o fortalecimento da Extensão Universitária está diretamente relacionado com a compreensão das especificidades desse fazer acadêmico e de sua vinculação com o Ensino e a Pesquisa.(FÓRUM DE PRÓ-REITORES DE EXTENSÃO DAS UNIVERSIDADES PÚBLICAS BRASILEIRAS, 2012, p.21)

Analisando brevemente os pontos destacados, diríamos que a extensão universitária pode ser delimitada ética e epistemologicamente a partir de alguns princípios norteadores. Em 
geral são algumas ideias fundamentais, reiteradas em documentos oficiais que versam sobre o assunto, as quais podem ser classificadas como princípios formadores da ação extensionista, tais como: superação da desigualdade e da exclusão social; mobilização de conhecimentos que visem à transformação social; aproximação aos movimentos sociais; fortalecimento da educação básica; difusão dos valores de cidadania. Todos conceitos afins aos ideais libertários, democráticos e emancipatórios que deveriam pautar as reflexões acadêmicas atuais. Se é verdade, portanto, que andamos distantes de práticas pautadas por esses ideais, parece conveniente pensar que as condições objetivas atuais apontam para a necessidade de ressignificar a extensão universitária. Isso quer dizer que ressignificá-la, no contexto de práticas sociais em geral hostis ao caráter gratuito da postura democrática, hostis à natureza coletiva das ações emancipatórias e libertárias, significa começar a pensar a extensão como ação pedagógica.

Sendo assim, de posse do que chamamos de princípios éticos e epistemológicos das práticas extensionistas convém, do ponto de vista metodológico, contrapor a essa concepção um outro entendimento das posturas de extensão. Posturas essas, muitas das quais estimuladas pelo Decreto $N^{o} 7.233$, de 19 de julho de 2010, o qual condiciona a alocação de recursos nas universidades federais à "existência de programas institucionalizados de extensão com indicadores de monitoramento", e que parecem ser a base em cima da qual se assentam as práticas e concepções de extensão que buscam seu espaço nas órbitas da academia. Temos aqui os traços de uma situação tipicamente paradoxal no nosso entendimento. De um lado os documentos oficiais pautando as políticas públicas, que conferem à ação da extensão uma dimensão libertadora e emancipatória dos sujeitos nela envolvidos. De outro, a aplicação dessas políticas de caráter mecanicista e antidialógico. A situação que aí se configura leva a concluir que até chegamos a pensar dialogicamente a extensão - como mostram as políticas públicas do FORPROEX, mas, na implementação da ação extensionista, quando esta é motivada exclusivamente por políticas governamentais, como o decreto mencionado, é que parece não haver dialogicidade. Que fazer, do ponto de vista educativo, ante a tal situação?

Retomando o já exposto, a situação parece obrigar-nos a ressignificar a extensão universitária. Para tanto, parece não mais fazer sentido pensar a extensão fora de sua dimensão pedagógica. Isso significar, indubitavelmente, assumirmos a postura de sujeitos do processo de extensão, de maneira que não mais o entendamos como um simples meio, um simples mecanismo, para se exercitar objetivos escusos ou alheios ao processo educativo. Assim como Manuel Bandeira definiu a matriz de sua poética no verso "Não quero mais saber 
de lirismo que não seja libertação", precisamos construir nossa matriz extensionista como prática educativa que conduza à libertação. Pois, no sentido que vem se formalizando historicamente, a ação extensionista é incapaz de promover uma ação educativa de caráter libertador, assim o define Paulo Freire (2011):

\begin{abstract}
Na medida em que, no termo extensão, está implícita a ação de levar, de transferir, de entregar, de depositar algo em alguém, ressalta, nele, uma conotação indiscutivelmente mecanicista. Mas, como este algo que está sendo levado, transmitido, transferido (...) é um conjunto de procedimentos técnicos, que implicam em conhecimento, que são conhecimento, se impõem as perguntas: será o ato de conhecer aquele através do qual um sujeito, transformado em objeto, recebe pacientemente um conteúdo de outro? Pode este conteúdo, que é conhecimento de, ser "tratado" como se fosse algo estático? Estará ou não submetendo o conhecimento a condicionamentos históricosociológicos? Se a pura tomada de consciência das coisas não constitui ainda um "saber cabal", já que pertence à esfera da mera opinião (doxa), como enfrentar a superação desta esfera por aquela em que as coisas são desveladas e se atinge a razão das mesmas? (FREIRE, 2011, p.26)
\end{abstract}

$\mathrm{Na}$ esteira desses questionamentos, caberia ainda interrogar como reposicionar a questão da extensão universitária se temos visto que à educação formal capitalista interessa tão-somente perpetuar os parâmetros reprodutivos gerais do sistema do capital? Se temos visto que as reformas são meros mecanismos estatais para manter o círculo vicioso da lógica autocentrada do capital? Como pensar a extensão enquanto ação pedagógica em face dos mecanismos de internalização de que dispõe o Estado capitalista para disseminação do consenso?

A questão parece confrontara necessidade de se repensar a extensão como ação pedagógica com a de criar mecanismos para construção de uma práxis capaz de, no âmbito político-pedagógico da educação formal, articular objetiva e sistematicamente atividades de contrainternalização. Hercúlea tarefa, todavia fundamental.

Precisamos, portanto, delimitar politicamente o papel da extensão como ação pedagógica; o que significa, no âmbito da educação formal, assumi-la objetivamente como atividade de contrainternalização. Nessa perspectiva, a extensão universitária não pode confundir-se com os mecanismos de produção de conformidade e consenso, os quais são as bases da educação formal capitalista para a reprodução dos parâmetros gerais do sistema do capital. 
Acreditamos que a extensão - mais que isso - necessitamos que a prática da extensão universitária possa construir-se enquanto agente progressista, disposto a romper objetivamente,e de forma duradora, com a dinâmica de internalização mantenedora da hierarquia social e das tarefas reprodutivas do sistema, as quais operacionalizam o controle social de condutas e consciências corretas e de expectativas adequadamente correspondentes a cada classe social.

Para que isso se efetive não basta boa vontade dos agentes envolvidos, pois as estruturas de poder e coerção da educação formal capitalista impõem aos trabalhadores da educação duras sanções, sobretudo aos que ousam violar o manual de instruções da máquina produtiva em expansão. Além disso, há de se ter consciência de que romper com a lógica do capital não é tarefa simples, tampouco tarefa exclusiva de quixotescos e esforçados educadores voluntariosos, mais ou menos conscientes de sua missão histórica. Posto está que para derrubar a atual ordem sócio-econômica metabólica são fundamentais ações conjuntas que visem a alterar todo o sistema de internalização em todas as suas dimensões visíveis e ocultas $^{2}$, o que jamais seria efetivado pela educação formal, tampouco em sua dimensão extensionista. Entretanto, anima-nos a convicção de que o hoje limitado e burocrático espaço da educação formal venha a se configurar espaço privilegiado para o exercício de conscientização em sentido amplo. Essa é a convicção que deve mover a extensão como ação pedagógica, convicção que, mesmo consciente de suas limitações no âmbito da educação formal, permanece criticamente animada pelo ímpeto de frear a histórica manipulação que vêm sofrendo homens e mulheres, dos quais é subtraído inescrupulosa e paulatinamente o direito de transformar o mundo.

$\mathrm{Na}$ opinião do professor Paulo Freire (2011), caberia ao educador o desafio e a necessidade premente de superar o conceito de extensão, em cuja aplicação se pretende a "domesticação dos homens", de modo a se chegar ao conceito de comunicação, à qual corresponderia a tarefa do educador. Poderia, a essa altura, um espírito mais atento perceber que Paulo Freire (2011) analisou o conceito à luz de um contexto específico de enunciação. Tratava-se, naquele caso, não do âmbito das instituições de ensino, mas da estrutura rígida e vertical latifundiária, a qual oprimia e emudecia o camponês, objeto das práticas de extensão rural, e que, portanto, esse deslocamento contextual não corresponderia aos anseios das políticas publicas.

Nesse caso, torna-se pertinente apontar que, em nossas práticas, também há sinais de que estariam reverberando os ecos de uma estrutura fechada e vertical, que em geral 
corresponde às estruturas funcionais dos ambientes de ensino, em que prevalece a burocracia. Convém pensarmos, com efeito, se nossas práticas de extensão (e de ensino e pesquisa) não são também reflexo de uma estrutura acadêmica latifundiária, que construiu historicamente consciências oprimidas por um tipo de saber, um tipo de conhecimento hermeticamente incomunicável, porque incapaz de transformar os sujeitos envolvidos em sujeitos da transformação.

Portanto, se interessa-nos compreender a ação pedagógica que deve integrar o saber extensionista - ainda que não tenhamos discutido a conveniência de se criar um conceito de comunicação também para as práticas acadêmicas -temos que criar mecanismos para defender nossas práticas das concepções mecanicistas. Pois os tecnicismos deste tipo de compreensão impossibilitam-nos a buscar a superação de estruturas verticais como as que temos nos referido. Contra a verticalização institucional da extensão, para qual interessa tãosomente acumular pontos para o curriculum, coordenar ações de extensão em pequenos números para almejar entrar na cota dos recursos rifados (quando há recursos para este fazer), para qual interessa gerar concorrência entre os pares, que passam a disputar entre si numa competitividade míope na qual não há comunicação nem troca de experiências; contra essa estrutura vertical, não nos parece descabida a ideia de que devemos motivar a articulação de todos os setores do saber. Nessa concepção, os saberes articulados pela extensão universitária são fruto de um processo de interlocução entre as diversas áreas do conhecimento humano, bem como dessas áreas com a atmosfera da interlocução.

Propor a extensão como atividade de contrainternalização pode significar - além de romper com o movimento que estende, mecânica e opressivamente, a visão de mundo hegemonicamente dominante - a possibilidade de, nos limites estreitos da educação formal, construir alternativas significativas de resistência à hegemonia ora dominante. Isto porque:

Se os elementos progressistas da educação formal forem bemsucedidos em redefinir a sua tarefa num espírito orientado em direção à perspectiva de uma alternativa hegemônica à ordem existente, eles poderão dar uma contribuição vital para romper a lógica do capital, não só no seu próprio e mais limitado domínio, como também na sociedade com um todo. (MÉSZÁROS, 2008, p.59)

O papel da educação formal, ainda que por ora peça indissociável do mecanismo de internalização, pode ser fundamental tanto para a elaboração de estratégias apropriadas e adequadas à mudança das condições objetivas de reprodução, quanto para a articulação de 
condições subjetivas para a criação de uma ordem social metabólica diferente e sustentável.Nesse sentido, articular uma ação de extensão é agrupar forças e não dividi-las ou subtrai-las. Se as instituições compreendem que devem atuar junto à escola básica, pode fazêlo em conjunto com a medicina familiar e com o futuro odontólogo, que neste entendimento também são educadores, com o estudante de direito, com o professor de agronomia, com o sociólogo, com o psicólogo, e com o politólogo, além, é claro, dos futuros professores das licenciaturas, desde que compreendamos nossos papéis como sujeitos da transformação, toda a ação em coalizão é valiosa. Se nos interessa articular o letramento digital com comunidades à margem da chamada inclusão tecnológica, por que não o fazermos de forma que desperte a ação problematizadora que há nas ciências aplicadas à computação e à tecnologia da informação. Pois, se não há ciência sem problematização, por que deve haver ciência da computação sem a prática dialógica? À medida que a universidade colabora para compreendermos o nosso entorno, o passo seguinte deveria ser motivar a saída do nosso próprio entorno. Se obstaculizamos essa travessia, estaremos sempre na iminência de transformar nosso conhecimento em acumulação latifundiária acadêmica.

\footnotetext{
${ }^{1}$ Aqui se faz referência aos princípios norteadores das atividades extensionistas, pactuados no âmbito do FORPROEX em 1987. O Fórum de Pró-Reitores de Extensão das Universidades Públicas Brasileiras trata-se do âmbito institucionalizado para delimitar e discutir periodicamente as Políticas Nacionais de Extensão Universitárias, em 1987.

${ }^{2}$ A Educação par Além do Capital de Mészáros defende este ponto de vista. Nas palavras do autor, precisa-se enfrentar todo o sistema de internalização com todas as suas dimensões visíveis e ocultas. O que implica substituir as formas onipresentes e profundamente enraizadas de internalização mistificadora por uma alternativa concretamente abrangente. (MÉSZÁROS, 2008, p.55)
}

\section{REFERÊNCIAS}

BRASIL. Constituição (1988). Constituição da República Federativa do Brasil. Texto consolidado até a Emenda Constitucional $n^{\circ} 70$ de 29 de março de 2012. Senado Federal. Disponível em: $<$ http://www.senado.gov.br/legislacao/const/con1988/CON1988_29.03.2012/CON1988.pdf>. Acesso em: 05 de junho de 2013.

Congresso Nacional. Lei n. 9.394, de 20 de dezembro de 1996. Estabelece as diretrizes e bases da educação nacional. Diário Oficial da União, de 23 de dezembro de 1996, p. 27.833 .

Disponível

em: 
$<$ http://portal.mec.gov.br/seed/arquivos/pdf/tvescola/leis/lein9394.pdf $>$ Acesso em: 05 de junho de 2013.

Presidência da República. Decreto 7.233, de 19 de julho de 2010. Dispõe sobre procedimentos orçamentários e financeiros relacionados à autonomia universitária, e dá outras providências. Diário Oficial da União, de 20 de julho de 2010. Disponível em: $<$ http://www.planalto.gov.br/ccivil_03/_Ato2007-2010/2010/Decreto/D7233.htm> Acesso em: 05 de junho de 2013.

FÓRUM DE PRÓ-REITORES DE EXTENSÃO DAS UNIVERSIDADES PÚBLICAS BRASILEIRAS. Politica Nacional de Extensão Universitária. Manaus/AM, maio de 2012. Disponível em: <http://www.renex.org.br/documentos/2012-07-13-Politica-Nacional-deExtensao.pdf $>$ Acesso em: 05 de junho de 2013.

FREIRE, P. Extensão ou Comunicação? 15 ed. Rio de Janeiro: Paz e Terra, 2011.

MÉSZÁROS, István. A Educação para Além do Capital. 2. Ed. - São Paulo: Boi Tempo, 2008.

I ENCONTRO DE PRÓ-REITORES DE EXTENSÃO DAS UNIVERSIDADES PÚBLICAS BRASILEIRAS, 1987, Brasília. Conceito de extensão, institucionalização e financiamento. Disponível em: <http://www.renex.org.br/documentos/Encontro-Nacional/1987-I-EncontroNacional-do-FORPROEX.pdf $>$ Acesso em: 05 de junho de 2013.

RECEBIBO EM: 18/09/2013

APROVADO PARA PUBLICAÇÃO EM: 14/09/2015 